\title{
NÚMEROS IRRACIONAIS NA ESCOLARIDADE BÁSICA: AS CONTRIBUIÇÕES DIDÁTICO-EPISTEMOLÓGICAS ADVINDAS DA HISTÓRIA DA MATEMÁTICA.
}

\section{IRRATIONAL NUMBERS ON BASIC EDUCATION: THE DIDACTICAL AND EPISTEMOLOGICAL CONTRIBUTIONS FROM HYSTORY OF MATHEMATICS.}

\author{
Wagner Marcelo Pommer \\ UNIFESP-Diadema/DCET/wagner.pommer@unifesp.br
}

\section{Resumo}

A apresentação e desenvolvimento dos números irracionais sofreram um processo de transposição didática muito simplificado e polarizado entre o pragmático e o teórico. Este texto objetivou analisar os contextos e contribuições histórico-epistemológicos dos números irracionais, de modo a situar como se apresentam os aspectos pragmáticos e teóricos surgidos ao longo do desenvolvimento do referido tema em livros de referência onde se encontram os 'saberes acadêmicos universitários', inspirados em Resende (2007). Realizamos uma busca em dois livros de referência: 'Conceitos Fundamentais da Matemática', de Caraça (1970) e 'As Ideias Fundamentais da Matemática', de Costa (1981). Caraça (1970) indica a possibilidade de se desenvolver o 'Problema da Medida', onde é possível se apresentar os segmentos comensuráveis e os segmentos incomensuráveis. Costa (1981) aponta para o desenvolvimento dos números irracionais por meio da reta real, questão que remonta a ideia de continuidade e ao corte de Dedekind. As narrativas presentes nesses livros podem contribuir para uma transposição didática com relação aos números irracionais. Em face de tais análises, centradas na narrativa e na abordagem qualitativa, destacamos alguns aportes que podem promover uma releitura dos fatos matemáticos, pela abordagem dos números irracionais por meio das ideias fundamentais representadas pelos pares contagem\&medida, finito\&infinito e exato\&aproximado.

Palavras-chave: Números Irracionais. Historia da Matemática. Bento de Jesus Caraça. Manuel Amoroso Costa. Ideias Fundamentais.

\section{Abstract}

Irrational numbers' presentation and development underwent a very simplified process of didactic transposition that is polarized between pragmatical and theoretical aspects. This text aimed to analyze the historical and epistemological contexts and contributions of irrational numbers, in a way to situate how it is presented the pragmatical and theoretical aspects revealed along the development of this theme on the references books where it is found the 'academical university knowledge', inspired in Resende (2007). We aimed our research on two reference books: 'Mathematics' Fundamentals Concepts', by Caraça 
(1970) and 'The Fundamental Ideas of Mathematics', by Costa (1981). Caraça (1970) indicated the possibility of addressing and developing the 'Incommensurable Measurement Problem', where it is possible to perform commensurable and incommensurable segments. Costa (1981) pointed to the development of irrational numbers by real number line, an issue that goes back to the idea of continuity and 'Dedekind cut'. The narratives discussed in these two books may contribute to a didactic transposition concerning to irrational numbers. Facing such analyzes, imbued on narrative and qualitative approach, we point out some contributions that can promote a retelling of mathematical facts, namely by approaching irrational numbers' by the fundamental ideas expressed by counting\&measure, finite\&infinite and exact\&approximate pairs.

Keywords: Irrational Numbers. Hystory of Mathematics. Bento de Jesus Caraça. Manuel Amoroso Costa. Fundamental Ideas.

\section{Introdução}

No campo da Matemática, os números representam uma ideia essencial, complexa e sofisticada. Thom (2004) ressalta que a construção do conhecimento matemático teve origem na Aritmética, que atualmente denominamos teoria Elementar dos Números, ramo que o autor aponta como um tipo de núcleo duro da área da Matemática.

Vale ressaltar que este aspecto apontado em Thom (2004) culminou em situar os números em uma posição cultural dentro da própria Matemática. Deste modo, a ideia de número ocupou uma posição privilegiada, do ponto de visto histórico e epistemológico, se constituindo como a:

[...] viga mestra da ciência. As extensões sucessivas do número obedeceram primitivamente ao intuito de criar símbolos adequados a representação de grandezas cada vez mais complexas. Certas generalizações, porém, nasceram da necessidade de atribuir sentido aos resultados das operações aritméticas (COSTA, 1929, p. 179).

Karlson (1961) e Caraça (1970) destacam que, no campo do ensino de Matemática Elementar, se optou por apresentar uma concepção inicial intuitiva com relação aos números. Nesse sentido, ao longo da escolaridade básica, os números são colocados aos alunos como elementos que surgiram a partir de registros pictóricos encontrados em diversos tipos de materiais da natureza ou produzidos por tribos e civilizações.

Posteriormente, no ensino básico são relatadas situações históricas que são relacionadas a processos de contagem e também de medida, de natureza pragmática, conforme relata Caraça (1970). O autor destaca que, no ensino usual, os aspectos de medida não são devidamente enfatizados, apesar da existência de vários registros históricos que indicam que o entendimento dos números se deriva da interação entre os aspectos de contagem e medida.

A polaridade intrínseca aos aspectos complementares e dialéticos relativos ao eixo contagem e medida pode ser identificada na epistemologia da Matemática pelo par discreto\&contínuo, apontado por Thom (2004) como a aporia fundamental da Matemática. 
Ao remetermos a origem etimológica de aporia, encontramos em Aurélio (2003) que 0 termo tem origem grega (a+poros), representando um conflito entre opiniões opostas, frente a uma mesma questão, mas que podem resultar em várias respostas. Thom (2004) acrescenta que a aporia representa uma oposição de fundo fundamental para promover maior compreensão para a área da Matemática.

No entanto, Machado (2009) aponta que a aporia presente no par discreto\&contínuo não se manifesta no desenvolvimento do ensino da Matemática. Até meados do Ensino Fundamental a polaridade se situa no discreto, mas, após o $7^{\circ}$ ano do Ensino Fundamental até o Ensino Médio, há uma tendência para o contínuo, sem articulação entre estes pólos.

No decorrer das etapas do ensino da Matemática, os estudos se direcionam para o entendimento e representação dos diversos sistemas numéricos desenvolvidos historicamente pelos povos antigos. Ainda, o currículo de Matemática aborda as leis de combinação que regulam os números, de modo a se estudar o comportamento desta entidade, os números, num universo essencialmente ligado ao pragmático.

Este tipo de escolha tendenciosa, privilegiando aspectos relacionados ao exato, finito, funcional, determinístico e previsível, realizado para o ensino dos números, encobre aspectos significativos e imprescindíveis ao estudo dos números e, em particular, representam um obstáculo didático para a introdução dos números irracionais e, em decorrência, dos números reais.

Para Brousseau (1983), o obstáculo didático se caracteriza pelas escolhas realizadas por um projeto concebido em um Sistema Educativo, porém que causam dificuldades ou estagnação ao aluno no ato de conhecer. No Sistema Educativo, os obstáculos didáticos podem ser identificados, por exemplo, nos manuais escolares ou na prática de ensino desenvolvido pelas escolhas do professor, dentre outros contextos.

O autor coloca que os obstáculos didáticos são resultantes de uma transposição didática inadequada, mas que o professor pode negociar na classe. $O$ reconhecimento dos obstáculos de origem didática permite ao professor, em sala de aula, ter ao dispor vários recursos para esclarecer ou contornar as possíveis dificuldades dos alunos.

Leviathan (2004) nos relembra que os números inteiros e racionais são estudados cuidadosamente na escola básica. Porém, na maioria dos livros didáticos de ensino básico, os números irracionais são abruptamente apresentados como sendo uma coleção de números reais que 'não' são racionais.

Ripoll (2001) aponta que esta definição circular introduzida no ensino básico, baseada no princípio da exclusão ou negação, além do natural caráter dúbio, inibe a exploração de algumas relações essenciais aos números irracionais.

Os livros didáticos da escolaridade básica se situam no que Chevallard (1999) chama de 'saber a ensinar'. Neste sentido, as pesquisas de Santos (2007), Souto (2010) e Pommer;Pommer (2012) apontam que a apresentação e desenvolvimento dos números irracionais geralmente enfocam situações pragmáticas, envolvendo a aproximação de resultados, sem maiores discussões. Estes resultados apontam uma grande simplificação no desenvolvimento dos números irracionais, como 'saber a ser ensinado'. 
Em contrapartida, outros manuais escolares introduzem e desenvolvem os números irracionais mediante definições e exercícios de fixação, o que caracteriza uma abordagem teórica. Como decorrência, poucos livros didáticos avançam para explorar as importantes possíveis relações entre os pólos pragmático\&teórico.

$\mathrm{Na}$ quase totalidade dos livros didáticos analisados por Santos (2007), Souto (2010) e Pommer;Pommer (2012), na faixa dos anos finais do Ensino Fundamental, a introdução dos números irracionais é realizada por meio das raízes enésimas irracionais. O enfoque das coleções se situa em contextos geométricos de áreas de figuras planas, 0 que geralmente se segue pela aplicação do teorema de Pitágoras e na apresentação das raízes quadradas. Alguns livros didáticos se baseiam em cálculos de volumes de sólidos, o que implica na resolução de uma raiz cúbica.

Em face destas constatações, este texto objetivou analisar os contextos e contribuições histórico-epistemológicos dos números irracionais, de modo a situar como se apresentam os aspectos pragmáticos e teóricos surgidos ao longo do desenvolvimento do referido tema em livros de referência.

\section{A transposição didática nos livros de referência}

O conceito de transposição didática, proposta por Chevallard $(1999,2001)$ coloca a didática no campo da antropologia e tendo como foco o olhar através do saber.

Para Chevallard $(1999 ; 2001)$, um saber que foi produzido por uma determinada instituição pode vir a ser utilizado em alguma outra instituição, seja ela de ensino ou não. Para tal, é necessário que este saber sofra transformações para se adaptar às condições deste novo meio. Chevallard (1999) denomina transposição a manipulação do saber que permite que ela sobreviva em outra instituição, e quando a instituição visada for a escola, esta é conhecida como transposição didática.

Neste sentido, a trajetória do saber perpassa três etapas: objeto de saber, objeto a ensinar e objeto de ensino. Neste modelo, um conteúdo de saber a ensinar sofre:

[...] um conjunto de transformações adaptativas que vão torná-lo apto a ocupar um lugar dentre os objetos de ensino. O 'trabalho' que de um objeto de saber a ensinar o torna um objeto de ensino, é chamado de transposição didática. [...] O estudo científico do processo de transposição didática (que é uma dimensão fundamental da Didática da Matemática) supõe levar em conta a transposição didática no sentido lato, representado pelo esquema: objeto de saber $\rightarrow$ objeto a ensinar $\rightarrow$ objeto de ensino (CHEVALLARD; BOSCH; GASCÓN, 2001, p. 39).

O 'objeto de saber' se situa no contexto onde o pesquisador (ou grupo) produz ou concebe um saber válido para a comunidade científica. Este é cunhado por Chevallard (1999) como 'saber sábio' ('savoir savant'), também conhecido como saber científico.

O 'objeto de saber' sofre um processo de descontextualização, despersonalização, organização e ordenação dos resultados, de modo a ligá-lo a outros saberes, tornando-o passível de ser transmitido de modo mais generalizado, no sentido de ser mais público ou universal. Este tipo de saber é encontrado em textos técnicos e descobertas científicas. 
Para Bosh e Gáscon (2001), o 'objeto a ensinar' é o oficialmente designado pelo sistema de ensino, através da Noosfera e materializado no currículo oficial. O 'saber', para poder (sobre)viver, passa por modificações, já que as condições do meio evoluem com o passar do tempo, de modo que "[...] as obras humanas evoluem e nunca acabam sendo exatamente como seus autores as propuseram" (CHEVALLARD, 2001, p. 117).

Para isto, uma comunidade denominada 'Noosfera', formada por autores de livros, autoridades, especialistas em educação, professores, pais, dentre outros, se encarrega da análise e pertinência da manipulação de um 'objeto de saber' em 'objeto a ensinar', de modo que "[...] uma obra seja ou não ensinada na escola é o resultado de decisões [...] tomadas pelos homens ao longo da história" (CHEVALLARD, 2001, p. 117).

O processo de transformação de um 'objeto de saber' em 'objeto a ensinar', tal como o que usualmente se encontra nos livros didáticos da educação básica, configura a transposição didática interna.

Para que se efetive o processo de transformação do 'objeto de saber' a 'objeto de ensino'1, de modo a que ocorra uma trajetória de viabilização do saber segundo moldes didáticos adequados, é possível aos estudantes adquirem conhecimento (learned available knowldge), conforme se observa no Quadro 01.

Quadro 01: The didactic transposition process [Fonte: BOSCH; GASCÓN, 2006, p. 56)].

\begin{tabular}{|c|c|c|c|}
\hline Scholarly Knowledge & Knowledge to be taught & Taught knowledge & $\begin{array}{l}\text { Learned, available } \\
\text { knowldege }\end{array}$ \\
\hline $\begin{array}{l}\text { Institutions producing } \\
\text { and using the knowledge }\end{array}$ & noosphere & Cla & Community of study \\
\hline
\end{tabular}

Outra contribuição advém de Resende (2007), que pontua que há saberes situados em um nível intermediário entre os 'saberes científicos' e os 'saberes a serem ensinados: são os 'saberes acadêmicos universitários', que são veiculados em disciplinas das Instituições do Ensino Superior.

Perrenoud (2000 apud Resende, 2007) considera que as disciplinas universitárias se constituem em um campo complexo imbricados no tripé ensino, saberes e práticas. Para o autor, as disciplinas do meio universitário são construtos sociais com fonte própria de legitimidade e com um estatuto epistemológico e praxeológico necessariamente conectado aos aspectos de ensino.

Inspirados em Resende (2007), que propõe que os saberes acadêmicos universitários' veiculados às disciplinas devam ser questionados, temos por hipótese que estes saberes podem ser averiguados se analisarmos o material didático de apoio as referidas disciplinas do Ensino Superior.

Em face das constatações que tecemos em relação aos livros didáticos de mercado editorial brasileiro para a escolaridade básica e também no fenômeno da transposição didática, neste texto nos propusemos a verificar como se apresenta o desenvolvimento histórico-epistemológico dos números irracionais em livros de referência

\footnotetext{
${ }^{1} \mathrm{O}$ 'objeto de ensino' é aquele efetivamente situado na aula pelos professores (Bosh;Gáscon, 2001).
} 
que podem ser utilizados nas licenciaturas, que constituem um possível material onde se situa os 'saberes acadêmicos universitários', que se situam em uma posição de mediação entre os 'objetos de saber' e os 'objetos a serem ensinados', propostos por Chevallard (1999).

Ponderamos quês estes livros de referência não estão situados no âmbito do domínio dos 'objetos do saber' pontuados por Chevallard (1999), pois são elaborados para apresentar o saber sábio em uma versão didática mais adequada ao público dos pesquisadores e dos alunos das licenciaturas, o que favorece a formação inicial de professores. Tão pouco, estes livros de referência não podem ser concebidos como 'saber a ensinar', visto que não são estruturados de acordo com os conteúdos e propostas curriculares oficiais para a escolaridade básica, servindo como fonte indireta para auxiliar o trabalho docente diante das tarefas do cotidiano escolar.

Em síntese, assim como as diversas pesquisas acadêmicas na área de educação, estes materiais que situam os 'saberes acadêmicos universitários' se constituem como apoio e possível referência didática para possibilitar e aprimorar a elaboração de aulas e situações de aprendizagem ou ensino, contendo, além de algumas considerações didáticas, fortes referências ao campo histórico e epistemológico.

Para promover uma melhor compreensão do contexto citado com relação aos números irracionais, realizamos uma busca em livros de referência, ou seja, manuais que se propõem a realizar uma análise de tópicos da Matemática sob um enfoque didático, histórico e epistemológico.

Neste mote, este texto teve como foco analisar os contextos e contribuições histórico-epistemológicos dos números irracionais, de modo a situar como se apresentam os aspectos pragmáticos e teóricos surgidos ao longo do desenvolvimento do referido tema nos livros de referência onde se situam os 'saberes acadêmicos universitários', apontados em Resende (2007).

\section{O papel da História frente ao conhecimento escolar}

A História do Conhecimento tem apresentado diversas pesquisas e tem surgido propostas para a utilização em sala de aula. Porém, há diversas posições para encaminhar e justificar seus procedimentos.

Costa (1981) relembra que a Matemática parece, para o leitor ingênuo, ter atingido um rigor e uma perfeição absoluta. Com toda a certeza, ninguém pode ignorar:

[...] que o método matemático por excelência é a dedução. Qualquer teoria matemática, uma vez construída, se exprime por uma cadeia de proposições que se implicam logicamente. Toda cadeia deste gênero exige, como ponto de partida, um sistema de noções não-definidas, em torno das quais serão eventualmente expressas outras noções, e um sistema de proposições não-demonstradas, ligando entre si as noções primitivas, e das quais se deduzirão, pelas leis da lógica formal, outras proposições chamadas teoremas. Devemos investigar preliminarmente a estrutura desses elementos iniciais, assim como os conceitos de definição e de demonstração, habitualmente expostos de modo pouco preciso (COSTA, 1981, p. 177). 
Porém, o referido autor acrescenta que a visão lógico-histórica do processo de elaboração do conhecimento matemático não deve necessariamente estar vinculada a apresentação didática da escolaridade básica.

Em meados do século $X X$, diversas pesquisas e práticas de sala de aula envolvendo o uso da História do Conhecimento se baseavam na lei biogenética de Haeckel (1834-1919). Este autor:

[...] buscou reconstituir o ciclo completo de evolução dos seres vivos desde os animais unicelulares até o homem. Baseado nesses estudos e nas idéias de Darwin, passou a defender que um embrião, ao se desenvolver, passa por todos os estágios evolutivos de seus ancestrais. Haeckel colocava o homem no alto da cadeia genealógica, considerando o progresso humano como uma conseqüência da evolução. Foi na obra "Os Enigmas do Universo" que ele expôs essas idéias condensando-as na chamada "lei biogenética fundamental", a qual, dizia que os seres vivos, ao longo do processo individual de desenvolvimento (ontogênese), recapitulam estágios do desenvolvimento da espécie (filogênese) (DAMBROS, 2006, p. 21).

Ao propor que 'a ontogenia recapitularia a filogenia', Haeckel suponha que o indivíduo repetiria as principais fases do desenvolvimento humano. Dambros (2006) destaca que a versão desta lei para o campo do ensino foi denominada de princípio genético, cuja origem é atribuída a Alexis Claude Clairaut (1713-1765).

O princípio genético coloca que se deveria incluir na experiência do aluno as principais etapas percorridas no desenvolvimento histórico das ideias, tal qual foram elaboradas no desenvolvimento epistemológico e lógico das disciplinas, conforme relato de Miguel e Miorim (1986).

Discordamos desta posição, acreditando que no âmbito escolar não deveria necessariamente haver uma transferência direta entre o desenvolvimento histórico de determinado conhecimento e a forma didática de abordar o conteúdo em sala de aula. $\mathrm{O}$ princípio genético não deve ser aplicado literalmente ao ensino de matemática, pois as origens históricas dos conceitos e os processos matemáticos não têm, naturalmente, necessidade de serem copiados para a abordagem pedagógica (Byers, 1982).

Outro ponto para ampliar a discussão se encontra em Schubring (2004). O autor faz uma reflexão sobre uma ilusão implícita nas abordagens sobre a história do ensino da Matemática: detectar, recolher, ordenar e revelar fatos em uma série cronológica, escondendo a complexidade inerente aos assuntos históricos.

Deste modo, um primeiro princípio para compreender a importância dos aspectos históricos para nortear o desenvolvimento de conceitos matemáticos é a não necessidade de submissão à linearização e temporalidade dos fatos históricos. Nesse sentido, os PCN destacam que a abordagem histórica não deve ser entendida como uma imposição de se:

[...] situar no tempo e no espaço cada item do programa de Matemática ou contar sempre em suas aulas trechos da história da Matemática, mas que a encare como um recurso didático com muitas possibilidades para desenvolver diversos conceitos, sem reduzi-las a fatos, datas e nomes a serem memorizados (BRASIL, 1998, p 42). 
Struik (1992) aponta que muitas contribuições advindas da história do conhecimento matemático foram omitidas ou se encontram demasiadamente simplificadas na concepção atual de ensino. Assim, a abordagem de temas no ensino básico com apoio em ideias historicamente construídas, poderia permitir uma reabertura com relação a práticas já adquiridas.

No cerne do desenvolvimento histórico do conhecimento matemático, que perpassou séculos, são encontradas respostas a diversas questões desafiantes e intrigantes que inquietaram muitos estudiosos e ainda desafiam os matemáticos atuais.

Salientamos que a escolha da utilização do recurso à história da Matemática permite entender que o conhecimento matemático não se desenvolveu cronologicamente. Os processos históricos sofreram revezes de acordo com as premissas e desenvolvimento de cada civilização face aos assuntos econômicos, culturais e científicos. Pode-se perceber que a História da Matemática foi construída como:

[...] resposta a perguntas provenientes de diferentes origens e contextos, motivadas por problemas de ordem prática (divisão de terras, cálculo de créditos), por problemas vinculados a outras ciências (Física, Astronomia), bem como por problemas relacionados a investigações internas à própria Matemática (BRASIL, 1998, p 40).

Outra contribuição com relação ao entendimento do necessário papel da História da Matemática advém do fato de que qualquer ciência poderia ser observada:

[...] sob dois aspectos diferentes. Ou se olha para ela tal como vem exposta nos livros de ensino, como coisa criada, e o aspecto é o de um todo harmonioso, onde os capítulos de encadeiam em ordem, sem contradições. Ou se procura acompanhá-la, no seu desenvolvimento progressivo, assistir à maneira como foi sendo elaborada, e o aspecto é totalmente diferente - descobrem-se hesitações, dúvidas, contradições, que só um longo trabalho de reflexão e apuramento consegue eliminar. [...] A ciência encarada assim, aparece-nos como um organismo vivo, impregnado de condição humana, com as suas forças e fraquezas e subordinado às grandes necessidades do homem na sua luta pelo entendimento; aparece-nos enfim, como um grande capítulo da vida humana social (CARAÇA, 1970, p. XIII).

Estas considerações podem ser transferidas para o campo educacional da escolaridade básica. Raths et al. (1977) atentam para uma crença errônea no campo do ensino que perdura até nossos dias: o aluno deve em primeiro lugar aprender os fatos para, depois, ser solicitado a pensar a respeito. Porém, muitas situações se tornam significativas quando as operações de pensamento são acessadas, pois "[...] pensar é uma forma de aprender. Pensar é uma forma de perguntar pelos fatos, e se o pensamento tem algum objetivo, os fatos assim encontrados serão significativos para esse objetivo" (RATHS et al., 1977, p. 15).

Raths et al. (1977) considera que a plenitude inerente ao ato de pensamento deve estar situada em contextos para promover e discutir os espaços ou territórios culturais da humanidade. Esta oportunidade se constitui em um tipo de experiência necessária e essencial ao desenvolvimento cognitivo do ser humano. 
Nesse sentido, os livros de História da Matemática poderiam se constituir em oportunidade de posicionar o pensamento do homem ao longo do desenvolvimento dos conhecimentos matemáticos e, assim, permitir aos alunos discutirem as distintas formas desenvolvidas por cada cultura antiga, para então comparar com a forma atual de apresentação da matemática, que derivada da tendência européia.

A disciplina denominada matemática é, na verdade, uma Etnomatemática que se originou e se desenvolveu na Europa mediterrânea, tendo recebido algumas contribuições das civilizações indiana e islâmica, e que chegou à forma atual nos séculos XVI e XVII, sendo, a partir de então, levada e imposta a todo o mundo. Hoje, essa matemática adquire um caráter de universalidade, sobretudo devido ao predomínio da ciência e tecnologia modernas, que foram desenvolvidas a partir do século XVII na Europa (D'AMBROSIO, 2005, p. 114).

Levando-se em consideração os números irracionais, cujo aperfeiçoamento matemático levou séculos, a forma usual de apresentação deste tema em muitos dos livros didáticos de ensino básico, sem vínculos com a gênese histórica é um dos fatores que causa dificuldades na aprendizagem deste conhecimento escolar.

Uma análise da gênese histórica permite facilmente se observar que:

[...] que os conceitos que têm sentido mais intuitivo, os números naturais, frações e conceitos geométricos, foram aceitos e introduzidos primeiro. Os menos intuitivos, os números irracionais, números negativos, números complexos, o uso de letras para coeficientes gerais e conceitos do cálculo exigiram muitos séculos para serem criados e aceitos. Além disso, quando foram aceitos, não foi a lógica que induziu matemáticos a adotá-los, porém os argumentos por analogia, o sentido físico de alguns conceitos e a obtenção de dos resultados científicos. A lógica sempre veio muito depois das criações (KLINE, 1976, p. 58).

Kline (1976) destaca que a história pode proporcionar uma perspectiva globalizadora e relacional dos tópicos das diferentes áreas. A apresentação dos conteúdos da disciplina de Matemática deixa de lado um aspecto básico ao oferecer uma apresentação lógica e organizada, que deixa a impressão para o leitor que os matemáticos vão de teorema em teorema de forma quase natural e podem resolver qualquer dificuldade.

Por outro viés, uma observação dos aspectos da história pode nos ensinar que o desenvolvimento de um tema faz-se pouco a pouco, muitas vezes por tentativa e erro, e com resultados que provém de diversas direções.

Para servir de suporte aos pressupostos encaminhados, realizamos uma escolha para situar e analisar as contribuições presentes em dois livros de referência envolvendo aspectos históricos e epistemológicos com relação aos números irracionais para o ensino básico. Este caminho constitui uma consideração essencial e fonte de recursos para ampliar as discussões para colaborar no aspecto de compreensão da noção de número irracional pelos alunos do ciclo básico, que fica irremediavelmente atrelada ao estabelecimento de uma salutar rede de conexões entre o pragmático e o teórico. 


\section{As escolhas dos livros de referência para análise dos números irracionais}

A ponderação e escolha dos livros 'As Idéias Fundamentaes da Mathemática',

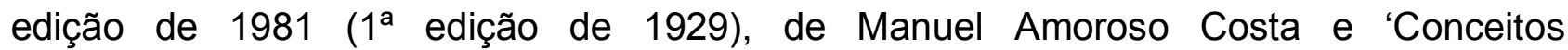
Fundamentais da Matemática', edição de 1970, Lisboa, de autoria de Bento de Jesus Caraça ( $1^{\text {a }}$ edição de 1941), se baseou em alguns aspectos peculiares.

Um primeiro motivo a se destacar é que os livros de Caraça (1970) e Costa (1981) tiveram como eixo balizador e estruturador uma narrativa envolta na explicitação das ideias ou conceitos matemáticos fundamentais. Esta opção didática dos autores revela uma preocupação no entendimento semântico dos números, um dos campos matemáticos mais antigos, através da apresentação de uma narrativa permeando as ideias fundamentais da Matemática. Deste modo, a abordagem delineada destes dois livros de referência onde se situam os 'saberes acadêmicos universitários' pode favorecer uma transposição didática em um contexto associado à língua materna - as narrativas em uma conexão interdisciplinar, opção pouco explorada nos manuais escolares voltados ao 'saber a ser ensinado', na escolaridade básica.

Um segundo ponto favorável em Caraça (1970) e Costa (1981) se faz com relação à escolha de uma narrativa matemática, fundamentada na conjunção de uma abordagem da história atrelada ao desenvolvimento epistemológico. Nestes livros de referência, os textos delineiam a evolução do campo dos números naturais, perpassando o campo dos Racionais, Irracionais e Reais, além de outros resultados da Teoria Elementar dos Números, assim como da Matemática em geral.

Estas características apontadas nos dois livros de referência representam uma forma de exposição do percurso histórico que permite a compreensão do surgimento dos números, em diversos povos, ligado às necessidades cotidianas e pragmáticas em relação à contagem de objetos, de mensuração de terra, de operações numéricas ligadas ao comércio, às questões tributárias e a partilha de bens.

Em contrapartida, os trabalhos de Costa (1981) e Caraça (1970) explicitam momentos da história onde são abordadas questões puramente abstratas da Matemática, como aquelas ligadas ao antigo povo grego, revelando conexões ao conceito teórico. Em relação a este viés, os dois livros de referência apontam situações presentes no percurso histórico do conhecimento matemático que permitem uma melhor compreensão da natureza dos números irracionais.

Esta opção das duas coleções representa uma forma alternativa que amplia a possibilidade de tratamento didático mais adequado dos números irracionais no ciclo básico, o que amplia o horizonte do campo da Aritmética (ou Teoria dos Números) no ensino básico.

\section{Os irracionais: As Contribuições Didático-Epistemológicas de Amoroso Costa}

Para Costa (1981), a descoberta da incomensurabilidade representa o grande marco pitagórico. No século $V$ a.C., os antigos gregos se defrontaram com a relação entre a diagonal e o lado do quadrado. Neste momento, os pitagóricos perceberam que estes segmentos não eram comensuráveis. Dois segmentos são ditos incomensuráveis se a 
razão entre estes não puder ser expressa como uma razão de números inteiros (com denominador não nulo).

O problema da incomensurabilidade entre a diagonal e o lado do quadrado não sintonizava com a concepção filosófica e cultural grega, onde todo número é inteiro ou era composto de uma relação simples entre inteiros. Para tal povo esta situação era indizível ou indenominável (alogon), ou seja, impossível de ser expressa com palavras e também inimaginável, pois não podia ser representada numa razão de números inteiros, uma premissa essencial para os pitagóricos. Este episódio, bem posteriormente, foi denominado 'A Crise dos Incomensuráveis'.

Os pitagóricos contornaram o impasse gerado por esta situação por meio de elementos geométricos. Este paradoxo poderia ter tido outro encaminhamento se os antigos gregos conhecessem dois ingredientes básicos: os conceitos "[...] do infinito matemático e da continuidade, noções que se impõem irresistivelmente ao espírito muito antes de poderem ser analisadas" (COSTA, 1981, p. 219).

Costa (1981) apresenta a dedução da incomensurabilidade entre a diagonal e o lado do quadrado, do modo que é exposto na transposição didática realizada em alguns livros didáticos do ensino básico.

A demonstração da sua incomensurabilidade, que se lê em Euclides, mas que Aristóteles dizia ser conhecida de Pitágoras, é um admirável exemplo de fusão entre o rigor lógico e a intuição geométrica, e merece ser reproduzida. Esta demonstração se faz por redução ao absurdo. Se a diagonal do quadrado é comensurável ao lado, a relação entre os dois comprimentos pode ser posta sob a forma de uma fração irredutível a/b. Tem-se que, por outro lado, em virtude do teorema de Pitágoras, sobre o quadrado da hipotenusa $a^{2}=2 . b^{2} ; a^{2}$ é pois um número par e, portanto, $a$ também é par, donde se conclui que $b$ é ímpar, porque $a$ e $b$ são primos entre si. Mas sendo a par, põe-se que $a=2 . \mathrm{k}^{\prime}$; daí resulta $4 . \mathrm{k}^{\prime 2}=b^{2} \mathrm{e}$, portanto, $b$ é um número par. Assim resulta a contradição (COSTA, 1981, p. 219).

Costa (1981) apresenta uma breve síntese das contribuições dos gregos.

Os gregos nunca chegaram, pois, a ter uma concepção clara do que nós chamamos hoje de número irracional. [...] Arquimedes inventou métodos que permitem construir duas sequências de números racionais, cujos termos são respectivamente inferiores e superiores ao irracional considerado, e diferindo deste tão pouco quanto se queira. É a origem da noção de número irracional definido como limite de uma sequência de números racionais (COSTA, 1981, p. 220).

A exploração desta argumentação qualitativa, tal como ocorre em Costa (1981) é apresentada em algumas coleções de livros didáticos, conforme constatação presente em Pommer;Pommer (2012). Porém, acreditamos que esta apresentação possa ser ampliada através do viés quantitativo, através de planilhas eletrônicas como o Excel, que serviria de suporte para sedimentar a constatação qualitativa descrita em Costa (1981).

Costa (1981) tece um breve comentário do uso pragmático de certos símbolos como $\sqrt{2}$ pelos antigos hindus (no século XII) e para os europeus ocidentais da época medieval, onde os números irracionais eram apenas números surdos ou fictícios, utilizados apenas para fins operacionais em cálculos numéricos. 
Costa (1981) aponta em Renè Descartes:

[...] uma decisiva mudança de orientação, pelo abandono do ponto de vista dos antigos. Descartes fez a observação fundamental que o resultado de um cálculo qualquer, efetuado sobre quantidades que se representam por grandezas retilíneas, pode ser igualmente representado por uma grandeza retilínea (COSTA, 1981, p. 220).

Assim, Descartes sistematizou as contribuições anteriores, originada a partir dos pitagóricos, para o estabelecimento e compreensão da natureza dos números reais.

O ponto de vista cartesiano é o número como medida de grandeza; os números reais se concebem como medindo segmentos de uma reta, na qual foram escolhidos uma origem e um segmento unidade, e os irracionais correspondem aos segmentos incomensuráveis ao segmento unidade" (COSTA, 1981, p. 221).

Costa aponta que esta interpretação métrica apresenta uma dificuldade, qual seja, a de se mostrar que a aplicação das propriedades sobre os números racionais podem ser estendidas aos números irracionais. O passo seguinte foi dado posteriormente por Cantor, pela ideia de continuidade geométrica, conhecido por postulado de Cantor-Dedekind, que direcionou os números irracionais a uma caracterização aritmética pela introdução da metáfora do corte.

Para entender essas ideias desenvolvidas por Dedekind, Costa (1981) expõe a possibilidade de repartir um dado conjunto racional $X$ (o 'corte de Dedekind') em dois conjuntos $A_{1}$ e $A_{2}$, de modo que cada racional $x \in X$ poder pertencer a $A_{1}$ ou a $A_{2}$ e sendo qualquer número racional de $A_{1}$ inferior a qualquer número de $A_{2}$.

Para demonstrar a natureza irracional de $\sqrt{2}$, um número que surge com freqüência na maioria dos livros didáticos, os manuais escolares poderiam fazer uso da ideia de 'corte de Dedekind'. Esta abordagem possibilitaria o enriquecimento do trabalho com o tema dos números irracionais, pela efetivação de uma transposição didática advinda dos livros de referência dos 'saberes acadêmicos universitários', propostos em Resende (2007).

Considere $A_{1}$ o conjunto dos números racionais negativos, o zero e todos os racionais cujo quadrado seja inferiores a 2. Também, seja $A_{2} 0$ conjunto dos racionais positivos tal que o quadrado seja superior a 2 .

Pelas considerações feitas, em $A_{1}$ não existe nenhum número racional que seja o maior de todos aos elementos de $A_{1}$. Também, em $A_{2}$ não existe nenhum número racional que seja o menor de todos os elementos de $A_{2}$. Nestas condições, o corte realizado em dois conjuntos $A_{1}$ e $A_{2}$ é aberto e define um número irracional, no caso, $\sqrt{2}$.

Este modo de apresentação representa um modo de introduzir os números irracionais em conjunção com os números racionais. Esta forma de abordagem destaca elementos de complementaridade e interação destes os números racionais e irracionais, pois: 
[um número] racional ou [um número] irracional pode ser considerado como par de conjuntos infinitos de números racionais. E como o número racional se exprime em termos do número inteiro, a concepção de Dedekind nos permite finalmente conceber o número irracional como uma arquitetura de números inteiros (COSTA, 1981, p. 237).

Podemos argumentar a favor da introdução desta apresentação do 'corte de Dedekind' no ensino básico, pois a mesma utiliza argumentação acessível a alunos do ciclo básico: os Conjuntos Numéricos. Ainda, a apresentação dessa narrativa permitiria ampliar o conceito de reta real, originada a partir do trabalho de Renè Descartes, algo não realizado na maioria dos manuais escolares atuais.

De modo geral, as ideias apresentadas por Costa (1981) introduzem uma possibilidade de narrativa baseada em argumentação e dedução simples e direta, implicando que a Matemática é uma área passível de ser acessível por meios qualitativos. Este tipo de abordagem dos livros de referência dos 'saberes acadêmicos universitários' se constitui uma ideia essencial para se efetivar uma transposição didática para o saber a ser ensinado, algo geralmente evitado nos livros didáticos de Matemática da escolaridade básica.

\section{Os irracionais: As Contribuições Didático-Epistemológicas de Caraça}

Caraça (1970) argumenta que a essência do conjunto dos Números Reais, que equivale ao trabalho com os números irracionais, encontra-se na 'Crise dos Incomensuráveis', ou seja, na crítica ao 'Problema da medida'.

Na definição canônica, Caraça (1970) argumenta que medir consiste em comparar duas grandezas de mesma espécie. Caraça (1970) expõe no livro que a incomensurabilidade entre segmentos poderia ser apresentada através do desenvolvimento do seguinte problema: São dados dois segmentos $A B$ e $C D$ tais que $A B$ é maior que $C D$. É possível medir $A B$, utilizando $C D$ como unidade?

Se tal questão for analisada do ponto de vista teórico, ou seja, pelo crivo da razão, há dois possíveis desdobramentos. Caso a resposta seja afirmativa, CD caberia um número exato de vezes em $A B$ e teríamos a representação do segmento $C D$ em relação ao segmento $A B$ em termos de números naturais.

Historicamente, a primeira evolução da 'arte de medir' poderia ser analisada ao se constatar a insuficiência dos números naturais para expressar alguns resultados. A necessidade de exprimir o resultado de uma medida como um número propiciou a mudança do âmbito do conjunto dos naturais para os racionais, uma consequência do princípio de extensão² apontado em Caraça.

Em caso contrário, caberia uma nova questão: é possível dividir $C D$ num número finito de partes iguais, de modo que uma dessas partes coubesse um número exato de vezes no segmento $A B$ ?

\footnotetext{
2 O princípio da extensão representa uma possibilidade de explicar certas propriedades dos conjuntos numéricos. Segundo Caraça (1970), todo trabalho intelectual da humanidade é orientado por certos princípios. Para escolher novas definições de um modo conveniente, o princípio de extensão procura adequar definições antigas com o dispêndio da mínima energia, abarcando o caminho mais rápido e curto. O princípio da extensão revela a tendência do homem a adquirir, a completar, "[...] a generalizar e estender todas as aquisições do seu pensamento seja qual for o caminho pelo qual essas aquisições se obtêm, e a procurar o maior rendimento possível dessas generalizações pela exploração metódica de todas as suas conseqüências" (CARAÇA, 1970, p. 10).
} 
Considerando-se o ponto de vista teórico, se ocorrer uma resposta afirmativa, surge uma fração imprópria $m / n$, com $m>n$. Neste caso, os dois segmentos são ditos 'comensuráveis' e remetem aos números racionais. Assim, existiria um segmento ' $u$ ' contido $\boldsymbol{m}$ vezes em $A B(m \in Z)$ e $\mathbf{n}$ vezes em $C D(n \in Z)$. Então $A B=m^{*} \boldsymbol{u}$ e $C D=n^{*} \boldsymbol{u}$. Neste caso, se diz que $\boldsymbol{u}$ é um submúltiplo comum de A e B.

$\mathrm{Na}$ figura 01 observam-se dois segmentos $A B$ e $C D$, de comprimentos $\boldsymbol{a}$ e $\boldsymbol{b}$, respectivamente. Se uma unidade $\boldsymbol{u}$ puder ser estabelecida de modo que a unidade $\boldsymbol{u}$ cabe $\boldsymbol{m}$ vezes no segmento $A B$ e $\boldsymbol{n}$ vezes no segmento $C D$, então temos: $\frac{A B}{C D}=\frac{a}{b}=\frac{m^{*} u}{n^{*} u}=\frac{m}{n}$, que remete a uma relação entre inteiros.
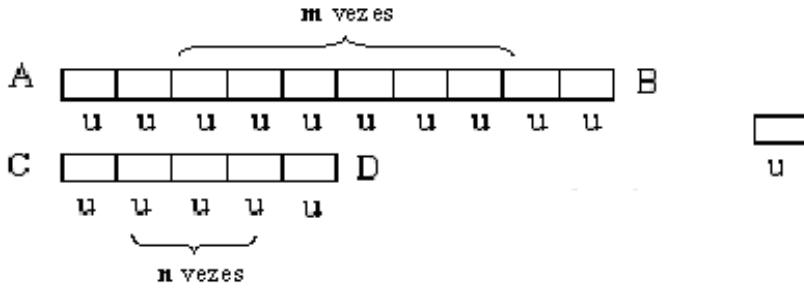

Figura 01: Representação de segmentos comensuráveis [Adaptado de Caraça (1970)].

Ocorrendo uma resposta negativa à questão proposta por Caraça (1970), não é possível dividir $C D$ num número finito de partes iguais, de modo que uma dessas partes caiba um número inteiro de vezes em $A B$. Esta situação representa 0 caso dos segmentos incomensuráveis.

A profundidade do 'Problema da medida' exposto em Caraça (1970) abrange maiores explicações do que o encontrado usualmente na maioria dos livros didáticos, onde a introdução dos números irracionais no ciclo básico recai na definição: os números irracionais são os números reais que 'não' podem ser expressos na forma $a / b$, onde $a$ e b são inteiros e $b \neq 0$.

Voltando a questão inicial proposta por Caraça (1970), se tal indagação for analisada do ponto de vista prático, a resposta sempre seria sim. Tal situação pode ser encaminhada analisando que:

[...] quando se aumenta o número de partes em que se divide $C D, O$ comprimento de cada uma delas diminue e chega uma altura em que a precisão limitada dos instrumentos de divisão e de medida não nos permite ir além de certo comprimento mínimo [...]. A parte de alíquota comum existe, portanto, sempre; se não tiver sido encontrada antes, é o segmento de comprimento mínimo que praticamente se pode obter. Assim, este resultado impõe-se a nossa intuição (CARAÇA, 1970, p. 49).

Do ponto de vista prático, há a possibilidade de se trabalhar a ideia de medida associada à exatidão ou a aproximação, que enriquece o repertório de conhecimentos ao situar e demarcar o conjunto dos números racionais e dos números irracionais, no âmbito da Matemática. Se estendermos esta posição a outras áreas do conhecimento, o ponto de vista prático permite ampliar o domínio do eixo exato\&aproximado, sob um enfoque interdisciplinar, algo extremamente desejável no ciclo básico. 
A abordagem prática permite delimitar o que se entende por uma boa aproximação e quais as várias possibilidades de encaminhamento possíveis de serem propostas. Assim, o tema 'medidas' constitui um aspecto que resgata uma relação essencial entre o conjunto dos números racionais e dos números irracionais. Porém, a análise revelada em Pommer;Pommer (2012) constatou uma abordagem insuficiente do tema das aproximações nos livros didáticos do Ensino Fundamental e Médio.

A aproximação, uma ideia fundamental da Matemática, representa um importante fator que constitui a única via de acesso de um número irracional, um conceito teórico, ao nosso mundo pragmático dos números racionais, tema que poderia ser mais desenvolvido nos livros didáticos.

\section{Considerações Finais}

É notória a questão central, presente nos títulos - que permeiam os dois livros de referência que optamos por analisar: os 'Conceitos Fundamentais da Matemática', Caraça (1970), cuja $1^{\text {a }}$ edição remonta a 1941, desenvolvida em Portugal e, as Ideias Fundamentais da Matemática', proposto por Costa (1981) e lançado no Brasil em 1929. Primeiramente, vale destacar a singularidade da escolha envolvendo os conceitos ou as ideias fundamentais da Matemática, em obras separadas por tempo, em pelo menos duas décadas, e em lugares distintos.

O contato com os modos de exposição e desenvolvimento do tema, expressos nas narrativas desenvolvidas por estes dois autores, puseram em relevo respostas a questões fundamentais da área de Matemática, permitindo mostrar os caminhos trilhados pelos pensadores antigos frente a situações desafiantes e instigantes. Este mote pode servir de estímulo ao interesse dos alunos para adentrar o estudo, em nível de escolaridade superior, aos vários ramos da Matemática, área do conhecimento que ainda possui muitos problemas em aberto.

Pelas considerações expostas nos dois livros de referência analisados, que se dispuseram a permear o desenvolvimento histórico-epistemológico dos números irracionais, Caraça (1970) e Costa (1981) encontraram meios para uma abordagem didática deste tema na escolaridade básica. Vale relembrar que estes livros vão ao encontro a dois aspectos essenciais da área da História da Matemática: retomar a reflexão que permeou o intrincado desenvolvimento histórico dos números irracionais, que atravessou cerca de vinte séculos, e ainda semear a essência dos livros, que é proporcionar modos ou momentos para o leitor acessar e movimentar o pensar.

Deste modo, o estudo do percurso histórico realizado em Caraça (1970) e em Costa (1981) permitiram uma compreensão inicial do embate entre o pragmático e o teórico, questão crucial ligada ao entendimento da natureza dos números irracionais, possibilitando uma ponderação inicial para um tratamento didático mais adequado.

Ampliando estas observações destacadas nos dois livros de referência, as narrativas presentes nos textos de Caraça (1970) e Costa (1981) podem contribuir com a possibilidade de fomentar a cultura matemática em sala de aula. Este aspecto pode ser observado na oralidade presente nestas coleções, em um discurso que enfatiza a 
necessidade de um olhar de Matemática mais amplo que o aspecto técnico e preocupado somente com os fundamentos da Matemática.

Costa (1981) destaca que a Matemática causa uma impressão de perfeição absoluta para a maior parte da comunidade de estudantes. Porém, as contribuições desta área sofreram um processo de reconstrução contínua, que foram apagados nos registros dos livros didáticos atuais.

Destacamos nestes autores o estudo dos aspectos de contagem e medida, assim como das reflexões inerentes ao par finito e infinito, que se constituem como possíveis referências para significar os números irracionais, desde que enfatizados e situados na problemática de ensino da Matemática da escolaridade básica.

Essas situações históricas revelam que o exato e o aproximado conviveram durante séculos no cenário do conhecimento matemático. Porém, no ensino atual, a transposição didática do campo dos números irracionais foi realizada de modo a diluir a gênese do conhecimento matemático frente ao par exato\&aproximado, assim como com relação aos pares contagem\&medida, e finito\&infinito. Nesse sentido, os livros de referência de Caraça (1970) e Costa (1981) ainda têm muito a contribuir para a transposição didática dos atuais manuais escolares da escolaridade básica.

\section{Referências Bibliográficas}

AURÉLIO. O Dicionário da Língua Portuguesa: Século XXI. São Paulo: Editora Nova Fronteira, 2003.

BYERS, V. Porque Estudar História da Matemática? Tradução de Maria Q. Amoroso Anastácio e Eduardo Sebastiani Ferreira. In: Inst. J. Math. Educ. Sci. Technol, v. 13, n. 1, 1982, p. 59-66.

BOSH, M.; GASCÓN, J. Twenty-five years of the Didactic Transposition. ICMI Bulletin, n. 58, p. 51-65, jun. 2006.

BOYER, C. B. História da Matemática. 9. ed. São Paulo: Editora Edgard Blücher, 1991. BRASIL. Parâmetros Curriculares Nacionais: $3^{\circ}$ e $4^{\circ}$ ciclos do Ensino Fundamental: Matemática. Brasília: Secretaria da Educação Fundamental (MEC/SEF), 1998.

BROUSSEAU, G. Les obstacles epistèmologiques et les problemes em mathématiques. RDM, v.4, n.2, Grenoble, 1983, p. 165-198.

CARAÇA, B. J. Conceitos Fundamentais da Matemática. 5. ed. Portugal: Lisboa, 1970. CHEVALLARD, Y. El análisis de las prácticas docentes en la teoría antropológica de lo didáctico. Recherches en Didactique des Mathématiques, v. 19, n. 2, p. 221-266, 1999. CHEVALLARD, Y; BOSH, M.; GASCÓN, J. Estudar matemáticas: o elo perdido entre o ensino e a aprendizagem. Porto Alegre: Artmed Editora, 2001.

COSTA, M. A. As Idéias Fundamentais da Matemática e Outros Ensaios. 3. ed. São Paulo: Edusp, 1981. 
DAMBROS, A. A. Conhecimento do desenvolvimento histórico dos conceitos

Matemáticos e o ensino de matemática: possíveis relações. 2006, 193f. Tese (Doutorado em Educação), Universidade Federal do Paraná, Curitiba.

D’AMBROSIO, U. Sociedade, cultura, matemática e seu ensino. Educação e Pesquisa, São Paulo, v. 31, n. 1, p. 99-120, jan./abr. 2005.

KARLSON, P. A Magia dos Números. Rio de Janeiro: Editora Globo, 1961.

KLINE, M. O Fracasso da Matemática Moderna. Tradução de Leônidas Gontijo de Carvalho. São Paulo: IBRASA, 1976.

LEVIATHAN, T. Introducing real numbers: when and how? Proceedings of ICME 10, 2004. MACHADO, N. J. Sobre alguns desequilíbrios na apresentação da Matemática básica: discreto/contínuo, finito/infinito, exato/aproximado, determinístico/aleatório. São Paulo: IMEUSP, 2009.

MIGUEL, A.; MIORIM, M. A. O ensino da matemática no primeiro grau. São Paulo: Atual, 1986.

POMMER, W. M.; POMMER, C. P. C. A abordagem de alguns números irracionais notáveis nos livros didáticos do ensino fundamental e médio. Interfaces da Educação, Paranaíba, v.2, n.6, p. 5-22, 2012.

RIPOLL, C. C. A Construção dos Números Reais nos Ensinos Fundamental e Médio. UFRGS, 2001.

RATHS, L. E. et al. Ensinar a Pensar. 2. ed. São Paulo: EDUSP, 1977.

RESENDE, M. R. A Teoria Elementar dos Números na Formação de Professores. 2007. 281f. Tese (Doutorado em Educação Matemática). Pontifícia Universidade Católica de São Paulo, São Paulo.

SANTOS, J. C. Números Reais: Um desafio na educação básica. Centro de Estudos Gerais, Instituto de Matemática. Niterói, 2007.

SOUTO, A. M. Análise dos Conceitos de Número Irracional e Número Real em Livros Didáticos da Educação Básica, 2010. Dissertação (Mestrado em Ensino de Matemática). Instituto de Matemática, Universidade Federal do Rio de Janeiro, Rio de Janeiro.

SCHUBRING, G. Pesquisar sobre a história do ensino da matemática: metodologia, abordagens e perspectivas, 2004. In: SPIEM, Portugal, 2004. Disponível em:

$<$ http://spiem.pt/DOCS/ATAS ENCONTROS/2004/2004 01 GSchubring.pdf >. Acesso em 04 abr. 2015.

STRUIK, D. J. História Concisa das Matemáticas. 2. ed. Tradução de João Cosme Santos Guerreiro. Lisboa: Gradiva, 1992.

THOM, R. A Aporia Fundadora das Matemáticas. In: Enciclopédia Einaudi, 2004, v. 43, p. 650-664. 
